\title{
DA TEORIA DO RISCO CONCRETO A TEORIA DO RISCO ABSTRATO NA SOCIEDADE PÓS-INDUSTRIAL: UM ESTUDO DA SUA APLICAÇÃO NO ÂMBITO DO DIREITO AMBIENTAL
}

\author{
Silvana Colombo ${ }^{1}$ \\ Vladimir Passos de Freitas ${ }^{2}$
}

\section{Resumo}

No Brasil, a questão ambiental passou a ter relevância jurídica, pois o direito de viver num ambiente ecologicamente equilibrado foi erigido à categoria de Direito Humano Fundamental. Sob a perspectiva da Constituição Federal e da teoria desenvolvida por Ulrich Beck, o presente artigo analisa a Teoria do Risco Abstrato na sociedade pós-industrial. Após uma breve abordagem acerca da crise ambiental, estabelece as condições necessárias para sua aplicação no que se refere a imputação da responsabilidade ambiental. Por fim, analisa-se o Princípio da Precaução, inserido no contexto de incerteza científica e imprevisibilidade dos riscos produzidos pela Sociedade.

Palavras-Chave: Risco - Teoria abstrata - Princípio da precaução - Dano ambiental.

\section{INTRODUÇÃO}

A ecologia global é um tema que está em voga. Isto porque as mutações engendradas pelas ameaças ambientais que pesam sobre o Planeta, como por exemplo, os riscos decorrentes da cadeia nuclear e os riscos ligados à biotecnologia deram uma repercussão planetária às questões ambientais. Como enfrentar estes problemas, já que muitos deles extrapolam os limites territoriais e temporais, mas também exigem um novo modo de agir do Direito em relação ao gerenciamento destes riscos ambientais.

Desta forma, nas páginas que seguem, procede-se um estudo acerca dos riscos que a Sociedade pósindustrial experimentaria, especialmente, os riscos de destruição do meio ambiente, que agora são caracterizados pela transtemporalidade e irreversibilidade, tendo como aporte teórico as ideias desenvolvidas pelo autor alemão Ulrich Beck e o texto da Constituição Federal.

\footnotetext{
${ }^{1}$ Doutoranda em Direito pela Pontifícia Universidade Católica do Paraná. Professora do curso de direito da UNOESC. E-mail: sil colonbo@ibest.com.br

2 Professor de Direito Ambiental no Programa de Pós-Graduação da Pontifícia Universidade Católica do Paraná. Doutor em Direito pela Universidade Federal do Paraná. Pesquisa de pós-doutorado na Faculdade de Saúde Pública da Universidade de São Paulo.E-mail: vladimir@passosdefreitas.com.br
} 
Inicialmente, aborda-se a crise ambiental que diante da impossibilidade de se dissociar dois elementos homem e meio ambiente -, porque ao mesmo tempo em que aquele depende deste, interfere na sua estrutura, de forma positiva ou negativa, o homem se vê obrigado a repensar sua forma de interagir com o meio ambiente.

A partir disso, chega-se ao segundo ponto, que trata da Teoria do Risco Abstrato, na Sociedade de Risco, como mecanismo aquedado para a imputação da responsabilidade civil ambiental, em relação aos danos ao meio ambiente já concretizados e também no sentido de prevenção e gerenciamentos dos riscos futuros.

O último ponto versa sobre o princípio da precaução, a saber, origem, conceituação e consequências, atrelado à Teoria do Risco Abstrato, já que o mesmo deve ser aplicado quando estiver presente certezas científicas razoáveis de que uma determinada atividade possa representar ameaças de danos sérios ao meio ambiente ou à saúde humana. Por fim, como decorrência da aplicação do referido Princípio, aborda-se a inversão do ônus da prova e o abrandamento do requisito da causalidade, para fins de imputação da responsabilidade civil ambiental.

\section{CRISE AMBIENTAL}

A primeira tarefa ao se referir à crise ecológica é dizer que "não há crise no uso da natureza que não seja uma crise no modo de vida do homem" (BACHELET,1995, p.4). Ou seja, o homem, como ser social, interage com o meio ambiente em que está inserido, como forma de garantir sua sobrevivência. Ao agir sobre os meios físicos, ele desencadeia um processo de transformação no meio ambiente, modificando seus elementos de forma positiva ou negativa. Esta interação se concretiza pelo trabalho que por sua vez transforma os bens presentes na natureza, a fim de satisfazer as necessidades humanas.

Neste sentido, Lukcás (2001, p.58) assevera que:

É pelo trabalho que o homem se destaca da natureza, numa processualidade cuja essência é a construção de um ambiente onde as categorias sociais predominam com intensidade crescente. Essência, por sua vez, que tem por base $o$ atributo de que toda atividade humana se constitui a partir de uma escolha entre alternativas, isto é, posições práticas metodologicamente orientadas, que, pela dinâmica inerente ao fluxo da práxis social, são generalizadas em complexos mediadores crescentemente socializados.

Por tudo isto, nega-se o caráter apenas utilitário e a atribuição de um valor meramente instrumental ou simplesmente de uso da natureza, o que significa dizer que não existe apenas um meio ambiente natural. Ou seja, a natureza não é simplesmente "utilizada e utilizável" e nem o homem é um ser isolado, como se fosse possível separar os seres humanos do meio ambiente natural.

Assim, durante muitos séculos o homem exerceu apenas uma relação de dependência com o meio ambiente em que estava inserido, contentando-se com sua generosidade ou não. Infere-se, então, que o mesmo limitou-se a suportar seu ambiente natural, o que contribuiu para manter intacto seus elementos, revelando uma "perfeita" harmonia entre homem e a natureza. 
Fustel de Coulanges (1963), na sua obra A Cidade Antiga, retrata com muita propriedade esta concepção de natureza, ou seja, o homem ao mesmo tempo em que se submetia a ela, se contentava com o que the era oferecido, eclodindo a ideia do divino: a natureza como algo sagrado, o que serviu de fundamento muito mais para preservá-la do que para conquistá-la.

Afirma o referido autor (1963, p.136):

A sua vida estava nas mãos da natureza; ele esperava a nuvem benfazeja de que se despendia a sua colheita, receava a tempestade que podia destruir o trabalho e a esperança de um ano inteiro; sentia todo o momento a sua fraqueza incomparável força daquilo que o rodeava, experimentava perpetuamente a uma mistura de veneração, de amor e de terror, para com essa poderosa natureza.

É bem verdade que a natureza até então tinha permanecido intacta especialmente nas suas potencialidades econômicas, numa época em que a natureza era divinizada pelo homem. De fato, a lenta conquista da natureza estava relacionada não somente aos poucos meios de agir que o homem dispunha sobre os elementos naturais e pela forte mitificação criada em torno da natureza, e do caráter sobrenatural atribuída a ela.

A exploração dos elementos naturais se desenvolve por meio dos avanços da ciência e da técnica. $\mathrm{O}$ processo de humanização e conquista, apesar de ter ocorrido de forma lenta, revelou-se extremamente destrutiva, ocasionando a degradação do meio ambiente sem precedentes.

Se os efeitos nefastos da ação do homem sobre o seu meio não podem ser atribuídos à sociedade atual, até porque muito provavelmente "nenhuma civilização tenha sido ecologicamente inocente" (DELÉAGE ,1992, p.252), pode-se dizer que o modo de produção agrícola, industrial e o aumento da capacidade nociva do homem contribuíram para o desencadear da crise ecológica.

De forma sintética, mas esclarecedora, o homem foi num primeiro momento submisso, depois utilizador, para então se tornar dominador (aparente) da natureza. A conquista da materialidade ecológica levou à destruição do meio ambiente, que num curto espaço de tempo foi saqueado e devastado pela ação humana. Ora, "estamos mergulhados numa crise ecológica que afeta o meio ambiente imediato dos seres humanos e os frágeis equilíbrios do planeta e aquela que afeta o desenvolvimento humano nos domínios econômico, social e cultural" (BRODHAG,1996, p.49).

Em meio ao ritmo alucinante da destruição do meio ambiente, ganha importância a conscientização ambiental, isto é, a necessidade de o homem conhecer e respeitar os limites que a natureza lhe impõe. Contudo, não se defende aqui a sujeição do homem à natureza e os movimentos ecológicos que têm como paradigma a deep ecology.

Seu principal defensor, Michel Serres (1994), parte do pressuposto de que a natureza como elemento vivo e sujeito que interage é também um sujeito de direitos. O contrato natural é um pacto estabelecido entre o homem e a natureza, isto é, "a natureza condiciona a natureza humana e vice-versa. A natureza se conduz como vol.08, no. 03, Rio de Janeiro, 2015.pp. 1895-1912 1897 
sujeito." E continua o autor: "é necessário situar as coisas no centro e nós na periferia, ou melhor, elas em todas as partes e nós em seu seio como parasitas" (SERRES,1994, p.61).

A resposta à ecologia profunda é um paradigma ${ }^{3}$ ecológico que impõe uma mudança em relação ao agir do homem sobre o meio ambiente e, sobretudo, uma mudança de valores e percepção. A incorporação de valores como a solidariedade e a ética requerem a superação da visão linear e reducionista do meio ambiente, inadequada para encontrar uma via intermediária entre a exploração de recursos esgotáveis e um futuro viável.

Um paradigma ecológico emergente se defronta com um olhar reducionista e pontual dos problemas ambientais, que separa o homem do ambiente natural e nega a complexidade das organizações sociais e do próprio meio ambiente. Neste sentido, Pelizzoli (1999, p.70) afirma que um paradigma ecológico emergente:

Retoma uma visão mais biocêntrica e ética, que traz novos e recuperados valores nas culturas e sociedades diversas, mas que acima de tudo visa àquela solidariedade socioambiental de que estamos falando, em vista de um século XXI suportável e com novo sentido para a vida na terra.

Sob esse ângulo o meio ambiente é um sistema complexo, que pode ser mais bem compreendido se o analisarmos a partir de um todo amplo, do que simplesmente considerarmos suas propriedades a partir de partes isoladas. Neste processo cíclico, o homem é um fio particular na teia da vida e deve estar aberto aos questionamentos sobre os fundamentos que permeiam sua visão de mundo e seu modo de vida. Para tanto, sua perspectiva ecológica deve estar centrada num pensamento holístico e não linear e em valores como a cooperação, conservação e parceria (CAPRA,1996).

À volta destas questões, na civilização-objeto o importante é a apropriação econômica da natureza e a lógica utilitária do seu aproveitamento. No entanto, é preciso ter presente que a modificação global dos equilíbrios do planeta abriu caminho para um repensar do homem sobre o modo de gerir o meio ambiente.

De fato, o alerta sobre a crise ecológica já era dado, em 1854, pelo cacique Seattle, em resposta à oferta do presidente dos Estados Unidos, Franklin Pierre (apud LEFF,2001, p.30), de comprar as terras dos índios:

Que seria o homem sem os animais? Se todos fossem exterminados, o homem também morreria de uma grande solidão espiritual. Porque o que acontece com os animais também acontecerá com o homem. Tudo está entrelaçado. Tudo o que acontece à terra, acontecerá aos filhos da terra. $\mathrm{O}$ homem não teceu a trama da vida, ele é apenas um fio.

Mas vocês caminharão para a destruição, rodeados de glória, inspirados na força de Deus que os trouxe a esta terra e que por algum desígnio especial lhes deu domínio sobre ele e sobre os peles-vermelhas. Onde está a floresta? Onde está a águia? Termina a vida e começa a sobrevivência.

\footnotetext{
3 "Os paradigmas são, [...] no sentido mais forte, grandes visões de mundo, que perpassam a mídia e a cultura de um povo e que orientam mesmo implicitamente seus passos e valores mais amplos e gerais. É aquele lugar de compreensão em que nós estamos situados e nos movemos, as condições construídas de acesso ao entendimento, de interpretação e de produção de realidade e daí para a prática [...]." (PELIZZOLI, 1999, p. 69).
} 
Para superar a crise do meio ambiente, mais do que uma estratégia de desenvolvimento sustentável ${ }^{4}$ é preciso conciliar a longo e curto prazo, o local e o global, e melhorar a eficácia das decisões políticas no plano econômico, social, cultural e ambiental. Além do mais, requer ainda a construção de uma ecologia global alicerçada na cooperação entre os povos e no respeito ao direito fundamental de viver num ambiente ecologicamente equilibrado

Além disso, o direito precisa gerar soluções para os problemas ambientais baseado na crescente complexidade em na prevenção dos danos ambientais. $\mathrm{O}$ complexo processo de gestão ambiental exige que os problemas ambientais sejam resolvidos não apenas com normas, mas como uma gestão que requer a inclusão de novos atores, transparência e fácil acesso às informações, perspectiva holística e multidimensional.

Neste sentido, no próximo item será abordada a Sociedade de Risco, especialmente, a Teoria do Risco Abstrato para fins de imputação da responsabilidade civil ambiental, à luz da teoria de Ulrich Beck.

\section{SOCIEDADE DE RISCO: A TEORIA DO RISCO ABSTRATO NA SEARA AMBIENTAL}

A ciência e a tecnologia são a causa dos principais problemas da sociedade industrial (BECK, 1995), isto é, se as instituições da sociedade industrial se preocuparam com a produção e distribuição dos bens e das riquezas, baseada no princípio da escassez, o mesmo não é possível afirmar em relação a produção e distribuição dos riscos ligados à produção industrial (BECK, 1995).

Neste sentido, a ordem social passa a ser regulada também pela distribuição de bens e também de riscos, tais como, os ecológicos, químicos, nucleares e genéticos, e também os econômicos. Este conjunto de riscos geraria "uma nova forma de capitalismo, uma nova forma de economia, uma nova forma de ordem global, uma nova forma de sociedade e uma nova forma de vida pessoal" (BECK, 1999, 2-7). Contudo, o direito, as instituições e a própria ciência se mostram incapazes de descrevê-los, o que dificulta a gestão destes riscos.

A ideia de risco relaciona-se a evolução tecnológica que conferiu às relações sociais maior rapidez e complexidade, fruto de um processo de industrialização e produção em massa, típico do sistema capitalista. Para Beck (1997, p.21). Os riscos "são formas sistemáticas de lidar com os perigos e as inseguranças induzidas e introduzidas pelo próprio processo de modernização. Estes são caracterizados pela ausência de fronteira territorial ou temporal, isto é, os mesmos são distribuídos para outras regiões, independentemente do local onde foram produzidos.

\footnotetext{
${ }^{4}$ PNUD - Programa Mundial das Nações Unidas para o Desenvolvimento. Relatório mundial sobre o desenvolvimento humano. Paris, 1991, p. 90. Define o desenvolvimento sustentável da seguinte forma: cada geração deve satisfazer as suas necessidades cotidianas sem contrair dívidas que não poderá reembolsar e sem comprometer a vida das gerações futuras.
} 
Neste contexto, a ideia de risco está associada ao processo de industrialização e ao conceito de modernidade ${ }^{5}$ reflexiva, definida por Giddens (apud BECK, 1995, p. 12) é "a possibilidade de uma (auto) destruição criativa para toda uma era: aquela da sociedade industrial". "O sujeito dessa destruição não é a revolução, não é a crise, mas a vitória da modernização ocidental” (BECK, 1995, p.12).

Para Beck, Giddens e Lash (1997, p.17) o conceito de sociedade de risco designa:

Um estágio da modernidade em que começam a tomar corpo as ameaças produzidas até então no caminho da sociedade industrial. Isto [...] [leva à] questão de rede terminar padrões [...] atingidos até aquele momento, levando em conta as ameaças potenciais. Entretanto, o problema que aqui se coloca é o fato de estes últimos não somente escaparem à percepção sensorial e excederem à nossa imaginação, mas também não poderem ser determinados pela ciência. A definição do perigo é sempre uma construção cognitiva e social. Por isso, as sociedades modernas são confrontadas com as bases e com os limites do seu próprio modelo até o grau exato em que eles se modificam, não refletem sobre seus efeitos e dão continuidade a uma política muito parecida.

Quanto a contextualização histórica do tratamento conferido aos riscos tecnológicos pelo Direito, destaca-se três momentos importantes no que se refere ao. Na primeira fase, o Direito desconsidera os riscos decorrentes da tecnologia, em função da preocupação com o desenvolvimento econômico, isto é, apenas os danos já concretizados objeto de decisão jurídica. (PARDO,1999).

Já na segunda fase, quando os riscos de degradação ambiental decorrentes da sociedade industrial se tornam visíveis, os riscos passam a ter relevância jurídica e permitem a intervenção corretiva quando da verificação da existência de um dano ao meio ambiente. É a concretização do dano que justifica a imputação da responsabilidade ao causador da lesão ambiental. (PARDO,1999).

Por fim, os graves riscos decorrentes da tecnologia pós-industrial conduzem ao tratamento prioritário dos mesmos pelo Direito, ou seja, não é necessário a concretização do dano ambiental para que este adquira relevância jurídica, já que "o risco se torna objeto de decisão jurídica autônoma". (CARVALHO,2008, p.14)

A sociedade industrial, baseada no paradigma da causalidade científica, isto é, na previsibilidade dos riscos industriais, serviu de suporte para o Direito priorizar os danos concretizados como requisito para a imputação da responsabilidade civil em material ambiental. É a denominada Teoria do Risco Concreto, baseada na responsabilidade civil objetiva. (CARVALHO,2008)

Contudo, a produção e distribuição de riscos mais complexos impõe ao Direito a necessidade de repensar sua forma de atuação, até então, pautada pela consideração dos riscos apenas depois de sua concretização. Em função das novas características dos riscos ambientais, a saber, o a invisibilidade, globalidade e

\footnotetext{
${ }^{5}$ Modernidade "significa a possibilidade de uma (auto) destruição criativa para toda uma era: aquela sociedade industrial. O 'sujeito' dessa destruição criativa não é a revolução, não é a crise, mas a vitória da modernização ocidental” (GIDDENS; BECK; LASH, 1997, p. 12).
} 
transtemporalidade, o Direito passa a adotar a Teoria do Risco Abstrato, que estabelece a necessidade de um dever de prevenção e de tomada de decisão anterior à concretização dos riscos em danos ambientais. (CANOTILHO,2004).

Nas palavras de Carvalho (2013.p.265):

Enquanto os riscos concretos são diagnosticáveis pelo conhecimento científico vigente, os abstratos encontram-se em contextos de incerteza científica. Para o gerenciamento dessas espécies de riscos, o direito ambiental prevê, respectivamente, os princípios da prevenção e da precaução, como programas de decisão.

Os problemas ambientais de primeira geração, marcados pela preocupação com a prevenção e controle da poluição ambiental (risco concreto), foram substituídos pelos direitos de segunda geração caracterizados pela preocupação dos aspectos globais da questão ambiental e nos efeitos colaterais das ações das presentes às futuras gerações (risco abstrato).

Assim, os riscos ambientais passam a ser considerados pelo Direito Ambiental como elemento para a tomada de decisão no sentido de prevenir a ocorrência dos danos ao meio ambiente. Este dever de prevenção encontra respaldo no artigo 225 da Constituição Federal, cuja tutela ambiental é elevada ao nível de um direito fundamental, e sua titularidade é das presentes e futuras gerações.

Menciona-se, ainda, que a partir da Teoria do Risco Abstrato, este dever de prevenção abrange a gestão dos riscos concretos e também dos riscos abstratos pelo Poder Público. Se os riscos concretos podem ser identificados pela certeza científica, os abstratos são diagnosticados pela incerteza científica.

A responsabilidade civil como instrumento de reparação de danos ambientais, pautado pelo Princípio da Prevenção, não é suficiente para atender os novos riscos, mais complexos e abstratos. Neste sentido, o princípio que permeia à Sociedade de Risco é o da Precaução, este preconiza que diante da incerteza científica, acerca das consequências advindas de determinada atividade, é necessário a adoção de medidas antecipadoras. (MORATO LEITE,2000)

Dito de outra forma, o Direito enfrenta dificuldade de lidar com a formação de novos riscos que surgem da Sociedade de Risco porque ainda continua a utilizar as conceituações teóricas próprias da Sociedade Industrial (CARVALHO, 2006). É o que preceitua Beck (2002, p.87):" En el umbral del siglo XXI, los desafios de la era de la tecnologia nuclear, genética y química se manipulan com conceptos y recetas derivadas de la primera sociedade industrial del siglo XIX y comienzos del XX".

Diante deste contexto, é necessário que o Direito estabeleça medidas que antecipem a ocorrência dos danos ambientais em razão das suas características, especialmente, a irreversibilidade e imprevisibilidade. Segundo Carvalho(2008) para que isto ocorra é necessário ser estabelecido critérios que permitam distinguir quais os danos que podem ser tolerados e quais devem ser considerados ilícitos em função da sua intolerabilidade. 
Ainda, segundo o referido autor (2008, p.154), o Princípio da proporcionalidade deve ser observada na definição dos riscos toleráveis ou intoleráveis:

O princípio da proporcionalidade consiste em programa de decisão jurídica utilizado como critério valorativo para a avaliação da licitude ou ilicitude dos riscos ambientais a partir da aplicação dos códigos probabilidade/improbabilidade; risco/benefício. Assim, a configuração ou não dos danos ambientais futuros e, consequentemente, da imposição de medidas preventivas dependerá da constatação da existência de riscos ambientais ilícitos.

Dito de outra forma, é preciso superar a Teoria do Risco Concreto, que incide quando da existência de um dano atual, para dar espaço a uma teoria que permite a judicialização de riscos, que apesar da incerteza científica, tem potencial lesivo. E nesta seara que emerge o papel do Direito que não pode ser omisso na sua tarefa constitucional de garantir as futuras gerações o direito de viver num ambiente ecologicamente equilibrado.

Uma das consequências decorrentes da utilização do Teoria do risco abstrato é a transição da responsabilidade objetiva, que exige a comprovação do dano para fins de reparação (PEREIRA,2012), para a responsabilização que possibilita a juridicização do risco, incluindo o dever de atuação preventiva

Conforme Carvalho (2006, p.211):

A Teoria do Risco Abstrato (de matriz sistêmica, tendo como principais autores Niklas Luhmann, Raffaele de Giorgi, e Ulrich Beck) tem a finalidade e função sistêmica de permitir a tomada de decisão antes da concretização dos danos, com base na superação da distinção risco/segurança para a distinção risco/perigo (e as distinções subsequentes à face do risco, ou seja, probabilidade/improbabilidade).

Cabe observar que a complexidade da sociedade atual traz reflexo nas descrições das relações sociais e jurídica de causalidade no que tange à responsabilização civil. Se a ciência moderna foi marcada pela previsibilidade da relação causa e efeito, a ciência atual encontra-se inserida numa realidade de incerteza cientifica e ausência de linearidade nas relações causais. (BECK, ano; CARVALHO,2006).

Dito de outra forma, na "modernidade o risco era social e institucionalmente percebido como um evento estático, provável, e, sobretudo, controlável” (AYALA, 2004 p.230), já atualmente o contexto é da imprevisibilidade. Esta é a razão pela qual se acentua a importância do tratamento conferido ao risco pelo Direito, que passa a considerar nas suas decisões tanto a imprevisibilidade quanto a incerteza científica diante de riscos ambientais intoleráveis. Para gerir estes riscos, o Princípio da Precaução se impõe como condição para prevenir o meio ambiente de um dano futuro. 


\section{O PRINCÍPIO DA PRECAUÇÃO COMO FUNDAMENTO DA TEORIA DO RISCO CONCRETO}

Os princípios $^{6}$ do Direito Ambiental orientam a elaboração de uma política ambiental adequada à realidade socioambiental do Estado. A compreensão dos seus princípios possibilita ao aplicador do Direito intervir de forma coerente nos litígios ambientais, ou seja, eles dão um sentido lógico e racional ao sistema jurídico.

Salienta-se, no que concerne à importância dos princípios, a lição de Canotilho (1998), ao destacar que a utilidade dos mesmos reside: (a) em serem um padrão que permite aferir a validade das leis, tornando inconstitucionais ou ilegais as disposições legais ou regulamentadoras ou atos que os contrariem; (b) no seu potencial como auxiliares da interpretação de outras normas jurídicas; (c) na sua capacidade de integração de lacunas.

No entender de Rehbinder (1973, p.155), "os princípios guardam a capacidade quando compreendidos como princípios gerais de influenciar a interpretação e a composição de aspectos cinzentos do direito ambiental". Dito de outra forma, os princípios devem orientar a aplicação das normas relativas à proteção do meio ambiente.

Importante frisar que os princípios do Direito Ambiental, adotados pela Constituição Federal, tiveram forte influência da doutrina alemã. E, conforme a referida doutrina, o direito do ambiente apresenta como aporte teórico três princípios fundamentais: o princípio da prevenção (vorsorge prinzip), o princípio do poluidorpagador ou princípio da responsabilização (verursacher prinzip) e o princípio da cooperação ou da participação (koopegrotions prinzip). (MUKAI,1998)

Apesar da relevância dos princípios supramencionados, destaca-se que o Princípio da Precaução é o principal norteador das políticas ambientais. O caráter irreversível, transfronteiriço e transtemporal dos riscos ambientais, conforme preceitua Beck(2002), impulsionou a criação de um parâmetro de limitação estes riscos, quando considerados intoleráveis. Ademais, o objeto central de proteção jurídico-ambiental refere-se aos possíveis efeitos da ação humana relativamente aos elementos naturais da vida e a respectiva retroação sobre os próprios homens.

Para Beck(2002), a sociedade de risco é marcada pela preocupação com os riscos decorrentes da atividade industrial e do desenvolvimento da ciência. Diferentemente da sociedade industrial, estes riscos apresentam como as características a irreversibilidade, a inexistência de limites fronteiriços e temporais, além da modificação do conceito de causalidade, já que as causas de um dano podem advir de fatos complexos.

\footnotetext{
${ }^{6}$ Princípio [...] é, por definição, mandamento nuclear de um sistema, verdadeiro alicerce dele, disposição fundamental que se irradia sobre diferentes normas compondo-lhes o espírito e servindo de critério para sua exata compreensão e inteligência, exatamente por definir a lógica e a racionalidade do sistema normativo, no que lhe confere a tônica e lhe dá sentido harmônico. (BANDEIRA DE MELLO 2003, p. 817-818)
} 
É neste contexto de imprevisibilidade e incerteza científica que emerge o Princípio da Precaução "que procura instituir procedimentos que permitem elaborar uma decisão racional na fase de incertezas e controvérsias, de forma a diminuir os custos sanitários dessa experimentação geral” (HERMITTE, 2005, p.15-16).

Quanto à previsão legal, o Princípio da Precaução está previsto expressamente, no ordenamento jurídico pátrio, no artigo $4^{\circ}$, I e IV da Lei da Política Nacional do Meio Ambiente (Lei 6.938/81), que trouxe a avaliação do impacto ambiental como requisito para a implantação de atividades e obras potencialmente leivas ao meio ambiente.

Igualmente, a Constituição Federal de 1988 incorporou o Princípio da Precaução no artigo 225, $\mathbb{1} 1^{\circ}$, V, ao determinar que incumbe ao Poder Público: "exigir, na forma da lei, para instalação de obra ou atividade potencialmente causadora de significativa degradação do meio ambiente, estudo prévio do impacto ambiental", para fins de garantir a efetividade do direito ao meio ambiente ecologicamente equilibrado.

No plano internacional, a Conferência das Nações Unidas sobre o Meio Ambiente e Desenvolvimento, realizada no Rio de Janeiro (1992) discutiu as medidas necessárias para a redução da degradação do meio ambiente. Deste modo, o Princípio da Precaução encontra-se inserido nos Princípios 15 e 17 da Declaração do Rio de Janeiro (1992), que expressam o seguinte:

Princípio 15: de modo a proteger o meio ambiente, o princípio da precaução deve ser amplamente observado pelos Estados, de acordo com suas capacidades. Quando houver ameaça de danos sérios ou irreversíveis, ausência de absoluta certeza científica não deve ser utilizada como razão para postergar medidas eficazes e economicamente viáveis para prevenir a degradação ambiental.

Princípio 17: a avaliação do impacto ambiental, como instrumento internacional, deve ser empreendida para as atividades planejadas que possam vir a ter impacto negativo considerável sobre o meio ambiente, e que dependam de uma decisão de autoridade nacional competente.

Além disso, a Declaração do Rio de Janeiro estabelece também a necessidade da Avaliação do Impacto Ambiental (AIA), quando for identificado ameaça de danos sérios ou irreversíveis ao meio ambiente. Resumidamente, essa é a essência do Princípio da precaução: em caso de certeza ou incerteza científica de danos ao meio ambiente deverá ser aplicado medidas ambientais de precaução.

Apesar da Declaração do Rio de Janeiro sobre Meio Ambiente e Desenvolvimento ser uma carta de princípios, portanto, os compromissos assumidos não são vinculantes na ordem interna dos Estados signatários, o Princípio da Precaução foi incorporado nas Convenções Internacionais de Mudanças Climáticas e Conservação da Diversidade Biológica. Desta forma, ele faz parte do direito costumeiro, fonte do Direito Internacional, e, portanto, é uma regra de jus cogens, já que o Brasil ratificou e incorporou a Convenção da Diversidade Biológica no direito interno. 
Outras Convenções, como a Convenção de Paris para a Proteção do Meio Marinho do Atlântico Nordeste (1992), bem como a Segunda Conferência Internacional do Mar Morto inseriram em seus textos o Princípio da Precaução (MORATO LEITE,2014). Conforme preconiza Trindade(1993), "os princípios oriundos das declarações internacionais são juridicamente relevantes e não podem ser ignorados pelos países na ordem internacional, nem pelos legisladores, pelos administradores públicos e pelos tribunais na ordem interna.”

É o que estabelece a Teoria do Risco Abstrato, a saber, diante de riscos ambientais globais que são, muitas vezes, irreversíveis e transnacionais, é preciso gerencias danos já concretizados e também os riscos futuros (BECK, 2002; CARVALHO, 2013). "Quando uma atividade representa ameaças de danos ao meio ambiente ou à saúde humana, medidas de precaução devem ser tomadas, mesmo se algumas relações de causa e efeito não forem plenamente estabelecidos cientificamente." (ANTUNES,2010, p.58).

Em relação à obrigatoriedade do Princípio da Precaução se manifesta Sands (apud DERANI,1997, p.76):

Apesar de não ser estritamente vinculante, muitas das regras (da Declaração do Rio) refletem princípios do direito costumeiro internacional, outras refletem princípios emergentes no direito internacional e, ainda outras, preveem orientações a serem incorporadas nos sistemas normativos internos e internacionais. A Declaração do Rio é a mais importante referência para se avaliar os futuros desdobramentos do direito internacional ao prover as bases para a definição do desenvolvimento sustentável e sua aplicação no plano do direito interno.

Nestes termos, a legislação ambiental acolhe o Princípio da Precaução como diretriz da política ambiental. Tal fato aponta para um posicionamento inovador do Estado em relação às questões ambientais, uma vez que o referido Princípio traduz a ideia inserta na Teoria do Risco Abstrato. Além dos danos produzidos pela sociedade industrial, a Ciência e a tecnologia expuseram os homens a novos riscos, que devem ser considerados pelo Direito porque não se justifica a lesão a presente e futuras gerações. (BECK,2002; CARVALHO,2013).

Posto isso, como pode ser definido o Princípio da Precaução? Precaução é agir com cautela, significa tomar uma decisão antecipadamente à probabilidade de ocorrência do dano ao meio ambiente. Isto significa dizer que o Princípio acima mencionado pode abranger tanto os riscos ambientais, que são produzidos pela ação do homem e vinculados à decisão deste, quanto os perigos, definidos como circunstâncias de fato, naturais ou não, que atingem a sociedade, tais como, os desastres naturais e pragas (BECK, 2002).

Convém, para a melhor compreensão do conceito de precaução, citar Derani (1997, p.67):

Precaução é cuidado. O princípio da precaução está ligado aos conceitos de afastamento de perigo e segurança das gerações futuras, como também de sustentabilidade ambiental das atividades humanas. Este princípio é a tradução da busca da proteção da existência humana, seja pela proteção de seu ambiente como pelo asseguramento da integridade da vida humana. A partir desta premissa, deve-se também considerar não só o risco eminente de uma determinada atividade, como também os riscos futuros decorrentes de 
empreendimentos humanos, os quais nossa compreensão e o atual estágio de desenvolvimento da ciência jamais conseguem captar em toda densidade [...].

A par destas considerações, afirma-se que o Princípio da Precaução deve ser aplicado frente a certeza científica do dano e também diante da incerteza científica, sendo que esta atinge a relação de causalidade entre o ato e suas consequências e também em relação ao risco e/ ou dano. Neste último caso, trata-se de gerir antecipadamente os riscos para o meio ambiente e também para o homem, isto é, atua-se para prevenir os efeitos adversos decorrentes de uma determinada atividade, seja para o meio ambiente, seja para o homem.

Feitas estas considerações preliminares sobre princípio da precaução, é preciso elucidar as diferenças entre prevenção e precaução, embora vez por outra a doutrina nacional utiliza tais termos como sinônimos. $\mathrm{O}$ termo prevenção ${ }^{7}$ remete à frase do senso comum "mais vale prevenir do que remediar", ou seja, o dano ao meio ambiente deve ser evitado antes de sua concretização, porque se conhece a consequência que surgirá em decorrência de uma determinada atividade. Já a precaução é aplicada quando há o risco de degradação do meio ambiente, mesmo que o nexo causal não tenha sido ainda estabelecido, em razão dos danos ambientais serem de difícil reparação (MILARÉ,2012).

No panorama do direito estrangeiro, a União Europeia faz a seguinte distinção da expressão prevenção/precaução:

Prevenir significaria evitar ou reduzir tanto o volume de resíduos quanto do risco ("avaid or reduce both volume of waste and associateal hazard"), enquanto que precaucionar seria uma obrigação de interveniência quando há suspeitas para o meio ambiente ("obligation to intervene once there is supcionus to the enviromment"), devendo neste último caso ocorrer intervenção estatal em relação ao risco. (TRINDADE,1993, p.65)

De fato, a aplicação de medidas ambientais diante da incerteza científica de um dano ao meio ambiente, prevenindo-se um risco incerto, representa um avanço significativo no que se refere à efetividade do conteúdo do Princípio da Precaução. Desta forma, consubstancia-se a substituição do critério da certeza pelo critério da probabilidade, ou seja, a ausência da certeza científica absoluta do dano ambiental não é um fator que possa impedir a aplicação das medidas ambientais (BECK; LEITE).

O princípio da precaução, enquanto princípio estruturante do Direito Ambiental e orientador da formulação de suas políticas, traz como primeira consequência o abrandamento do nexo de causalidade. A prova do vínculo entre a atividade de risco criado e o dano é dificultada pelos seguintes fatores: (i) a pluralidade de fontes poluidoras, já que tal fato poderá acarretar a não identificação e/ ou indeterminação do polo passivo da

\footnotetext{
${ }^{7}$ No Princípio da Prevenção previne-se porque se sabe quais as consequências de se iniciar determinado ato, prosseguir com ele ou suprimi-lo. O nexo causal é cientificamente comprovado, é certo, decorre muitas vezes até da lógica. No Princípio da Precaução previne-se porque não se pode saber quais as consequências que determinado ato, ou empreendimento, ou aplicação científica causarão ao meio ambiente no espaço e/ou no tempo, quais os reflexos ou consequências. Há incerteza científica não dirimida (MACHADO,2011, p.75).
} 
demanda ambiental. (ii) o dano pode "dificuldade de determinação da origem do dano ambiental ou dos males que a vítima apresenta", já que o dano pode advir de um emissor indeterminado; (iii) por fim, as consequências decorrentes do dano muitas das vezes se manifestam ao longo do tempo, representando uma lesão de modo continuado (ABELHA, 2004).

O aspecto importante do referido tema está no reconhecimento de que, regra geral, é admissível a presunção de causalidade, isto é, do vínculo entre a atividade desenvolvida pelo potencial poluidor e os danos ambientais constados. "Não abdicando da existência de um nexo causal entre a ação e o dano, o Direito do Ambiente vem fundar este elo em juízos de probabilidade séria, consubstanciados na experiência social (normalidade e adequação) e apoiados no conhecimento científico, abandonado a procura de uma causalidade certa e absoluta a que lhe é negado acesso”. (CRUZ,1997, p.41)

A título de exemplo, "cortes francesas, v.g., têm assentado a relação de causalidade em conjunto de presunções graves, precisas e concordantes, estabelecidas negativamente: não ter havido no momento do dano outro fato que o pudesse explicar, ou não existir entre a fonte possível de poluição e o local de verificação do dano qualquer outra instalação, que o pudesse provocar" (TJRS/2002).

Nem sempre o demandante consegue demonstrar claramente o ponto de contato entre a atividade do agente e o dano produzido. Vê-se, portanto, que, o insucesso das demandas ambientais está diretamente ligado à verificação no caso concreto da relação de causalidade entre o dano ambiental (efeito) e o potencial poluidor (causador). Por isso, os argumentos utilizados, especialmente o da presunção da causalidade, é bastante apropriado em matéria de dano ao meio ambiente e reproduzem o comprometimento dos tribunais brasileiros com o dever constitucional de proteção ambiental.

A segunda consequência da aplicação do Princípio da Precaução, é a inversão do ônus da prova. Em outras palavras, transfere-se ao demandado a necessidade de provar a inofensividade das atividades levadas à apreciação do Poder Judiciário. É o que determina esse Princípio $^{8}$ que impõe ao sujeito que desenvolve uma atividade potencialmente lesiva ao meio ambiente o ônus de provar que sua atividade não lhe oferece riscos. A inversão do ônus da prova, portanto, abarca a incerteza científica e também o risco incerto do dano ambiental, o que coaduna com a Teoria do Risco Abstrato (ABELHA 2003, MORATO LEITE,2004).

A jurisprudência também se manifesta de forma favorável em relação à inversão do ônus da prova, solidificando a teoria objetiva da responsabilidade civil:

Para o reconhecimento da responsabilidade civil da indústria poluente, é irrelevante a circunstância de estar ela funcionando com a autorização das autoridades municipais, ou fato de nunca ter sofrido autuações dos órgãos

\footnotetext{
${ }^{8}$ O Princípio 15 da Declaração de Princípios do Rio determina: "no caso de risco de danos graves ou irreversíveis, a falta de certeza científica absoluta não deve servir de pretexto para adiar a adoção de medidas efetivas que visem prevenir a degradação do ambiente"
} 
públicos encarregados do controle do meio ambiente. Mesmo sem levar em conta a notória deficiência dos serviços públicos, neste particular, forçoso é concluir que demonstrada a relação causa e efeito entre a exagerada missão de poluentes e os danos experimentados pelo autor, emerge clara e inafastável a responsabilidade civil da ré. (SEGUIM, 2009.p.19)

Nesse sentido, a inversão do ônus da prova, judicial e extrajudicial, é uma consequência da aplicação do Princípio da Precaução. A transferência do ônus da prova para os potenciais poluidores ocorreria nos seguintes casos: (a) quando ainda não se verificaram danos ao meio ambiente, todavia eles poderão vir a ocorrer, diante falta de prova científica; (b) quando os danos já ocorreram, porém não se tem conhecimento da sua causa principal; (c) quando os danos ocorreram, mas não há prova do nexo de causalidade entre o dano e a fonte poluidora (CANOTILHO,1998).

A inversão do ônus da prova, prática corrente no Direito do Consumidor, deve ser também aplicada no Direito Ambiental. Desta forma, a inversão do ônus da prova, em matéria ambiental, tem como fundamento o artigo 6 do CDC e também o inciso IV do artigo 1 da Lei de Ação Civil Pública (criado pelo artigo 110 do CDC). Esta lei passou a reger as ações de responsabilidade por danos tanto morais quanto patrimoniais causados a direitos coletivos e difusos.

Afirma-se, então, que a inversão do ônus da prova aplicada no Direito do Consumidor também deveria ser observada em matéria ambiental. Além do ônus probandi ser regra processual, a mesma também é arrolada como um direito básico ou fundamental do consumidor, ou seja, ela se ajusta ao Título III do CDC, referente às regras processuais e também ao artigo $6^{\circ}$, que trata dos direitos do consumidor.

Fiorillo, Abelha e Nery (1996, p.98) entendem que:

A relação entre o CDC e LAPC possui cunho visceral, pois suas regras processuais se aplicam aprioristicamente a toda ação coletiva, formando um sistema processual coletivo. Desta forma, é perfeitamente aceitável a aplicação da inversão ônus da prova em sede de qualquer ação coletiva, nesta incluídas aquelas para tutela do meio ambiente, pois a inversão do ônus da prova é regra de natureza processual e todos as regras processuais do CDC e da LAPC devem ser aplicadas na tutela de outros direitos difusos e coletivos, conforme os artigos 1, IV e 21 da LAPC.

Diante disso, entende-se que a facilitação da prova do nexo de causalidade, especialmente a inversão do ônus da prova, é bastante apropriada ao dano ambiental, pois transfere-se para o potencial poluidor o dever de provar a não lesividade de seu empreendimento. Ainda, a facilitação da prova do dano ambiental poderia ocorrer também sem a inversão do ônus probandi, por meio do critério de verossimilhança da prova produzida, que reduz o grau de exigência para o onerado.

Sobre este ponto, convém reforçar novamente que o Princípio da Precaução abarca a certeza e também a incerteza científica do dano, ou seja, "consiste em dizer que não somente somos responsáveis sobre o que nós sabemos, sobre o que nós deveríamos ter sabido, mas também sobre o de que nós deveríamos duvidar" (DERANI,1997,p.58).Portanto, é possível agir mesmo antes da Ciência dizer de forma absoluta se determinada vol.08, no. 03, Rio de Janeiro, 2015. pp. 1895-1912 1908 
atividade é nociva ou não ao meio ambiente, o que corrobora com o entendimento do Beck (2002) no que se refere ao enfretamento pelo Direito dos riscos produzidos na sociedade pós-industrial.

\section{CONCLUSÃO}

A passagem da Sociedade de Industrial para uma Sociedade de Risco, caracterizada pela possibilidade de danos ambientais transtemporais, globais, invisíveis e irreparáveis, traz a necessidade do Direito estabelecer mecanismos jurídicos que auxiliem na gestão destes riscos.

Todas estas peculiaridades dos riscos ambientais são importantes para consagrar a Teoria do Risco Abstrato como mecanismo jurídico a ser observado no que se refere a imputação da reponsabilidade civil mediante a existência de uma conduta de risco, não apenas quando o dano ao meio ambiente já estiver concretizado.

Atrelado à Teoria do Risco Abstrato encontra-se o Princípio da Precaução, reconhecido tanto pelo direito brasileiro quanto pelas convenções e tratados internacionais, o que vem corroborar com a implementação de uma política ambiental não apenas repressiva, mas, sobretudo preventiva. Antecipa-se à ocorrência do dano como forma de proteger ou tutelar também o risco incerto, desde que haja fundamentos razoáveis para aplicação das medidas preventivas.

Verifica-se, então, que a partir da consagração do Princípio da Precaução, desenvolveu-se uma nova concepção em relação à obrigatoriedade da comprovação científica do dano ambiental. Não há mais a necessidade da certeza científica absoluta, a contrário sensu, o referido Princípio aplica-se também para os casos em que há incerteza científica acerca dos efeitos negativos de uma atividade/obra.

Em vista do exposto, vale, também, atentar aos pontos falhos da teoria da responsabilidade civil em matéria ambiental, especialmente, a dificuldade de ser demonstrada a existência do nexo de causalidade entre a atividade causadora e o dano ambiental dela resultante. É neste contexto, que o Princípio da Precaução traz duas consequências importantes, o abrandamento do liame de causalidade e a inversão do ônus da prova nas demandas ambientais.

Quanto a inversão do ônus da prova, transfere-se para o demandado o ônus de provar que sua atividade não oferece riscos ao meio ambiente, na verdade, ele assume o risco de perder a causa se não provar os fatos alegados. Já em relação ao liame de causalidade entre a causa e o efeito do dano, mostra-se necessário a utilização do critério da verossimilhança, em razão da irreversibilidade e do caráter global dos riscos ambientais.

Por fim, entende-se que o direito precisa gerar soluções para os problemas ambientais baseado na crescente complexidade em na prevenção dos danos ambientais. O complexo processo de gestão ambiental exige 
que os problemas ambientais sejam resolvidos não apenas com normas, mas como uma gestão que requer a inclusão de novos atores, transparência e fácil acesso às informações, perspectiva holística e multidimensional.

\title{
THEORY OF CONCRETE RISK TO THEORY ABSTRACT RISK IN POST- INDUSTRIAL SOCIETY: AN APPLICATION OF YOUR STUDY IN ENVIRONMENTAL LAW SCOPE
}

\begin{abstract}
In Brazil, the environmental issue now has legal significance, since the right to live in an ecologically balanced environment was erected on Fundamental Human Right category. From the perspective of the Federal Constitution and the theory developed by Ulrich Beck, this article analyzes the Risk Theory Abstract in postindustrial society. After a brief overview about the environmental crisis, establishes the conditions for its application as regards the allocation of environmental responsibility. Finally, it analyzes the precautionary principle, inserted into the context of scientific uncertainty and unpredictability of the risks produced by the Company.
\end{abstract}

Keywords: Risk - Theory abstract - Principle of precaution - Environmental damage.

\section{REFERÊNCIAS}

ABELHA. Marcelo. Breves considerações sobre a prova nas demandas coletivas ambientais. In: DANTAS, Marcelo Buzaglo; LEITE, José Rubens Morato. Aspectos processuais do direito ambiental. Rio Janeiro: Forense Universitária, 2004.

ARENDT, Hannah. As origens do totalitarismo. Tradução de Roberto Raposo. Rio de Janeiro, 1999.

BANDEIRA DE MELLO, Celso Antônio. Curso de direito administrativo. São Paulo: Malheiros, 2003, p. 817 818.

BECK, Ulrich. La sociedade del Riesgo Golbal.Madrid:Siglo Vientiuno,2002.

A Reinvenção da Política: rumo a uma teoria da modernização reflexiva. In: GIDDENS, Anthony; BECK, Ulrich; LASH, Scott. Modernização Reflexiva. São Paulo: UNESP, 1995.

BRASIL, Tribunal de Justiça do Estado do Rio de Janeiro. Apelação Cível no. 16.035/2002. Relator: Luiz Roldão de Freitas Gomes. Acórdão Publicado no Diário da Justiça da União de 02 de out. de 2002. Disponível em: Http://www.stf.gov.br. Acesso em: 20 de jun., 2015.

BRASIL. Constituição da República Federativa do Brasil. 27. ed. São Paulo: Saraiva, 2006.

BRODHAG, Christian. As quatro verdades do planeta. Por uma outra civilização. Tradução de Newton Roberval Eichemberg. São Paulo: Cultrix, 1996. 
CANOTILHO, José Joaquim Gomes. Introdução ao direito do ambiente. Lisboa: Universidade Aberta, 1998.

CAPRA, Fritjof. A teia da vida, uma nova compreensão cientifica dos sistemas vivos. Tradução de Newton Roberval Eichemberg. São Paulo: Cultrix, 1996.

CANOTILHO, José Joaquim Gomes. Estado Constitucional Ecológico e Democracia Sustentada. In: MORATO LEITE, José Rubens; FERREIRA, Heline Sivini Ferreira (orgs.) Estado de Direito Ambiental: tendências. Forense Universitária: Rio de Janeiro, 2004.

CARVALHO, Délton Winter de. Dano ambiental futuro: a responsabilização civil pelo risco ambiental". Revista de Direito Ambiental. n. 45, jan-mar. p. 62-91, 2007.

Regulação constitucional e risco ambiental. Revista Brasileira de Direito Constitucional - RBDC n. 12 jul./dez. 2008.

Dano ambiental futuro: da assimilação dos riscos ecológicos pelo direito à formação de vínculos jurídicos intergeracionais.Tese do doutorado em Direito apresentado na Universidade do Vale do Rio dos SinosUNISINOS,2006.

COULANGES, Fustel de. A cidade antiga. Reedição Hachette, 1963.

CRUZ, Branca Martins da. Responsabilidade civil pelo dano ecológico: alguns problemas. Revista de Direito Ambiental. São Paulo, ano 2, v.5, p.05-41, jan./mar.,1997.

DELÉAGE, J. Paul. Une historie del' écologie la découverte. Paris, 1991.

DERANI, Cristiane. Direito ambiental econômico. São Paulo: Max Limonad, 1997.

FIORILlO, Celso Antônio Pacheco; ABELHA, Marcelo; NERY, Rosa Maria Andrade. Direito Processual ambiental brasileiro. Belo Horizonte: Del Rey, 1996.

GIDDENS, Anthony; BECK, Ulrich; LASH, Scott. Modernização Reflexiva. São Paulo: UNESP, 1997.

HERMITTE, M.A. Os fundamentos jurídicos da sociedade do risco: Uma análise de U. Beck. In: Governo dos Riscos / Rede Latino - Americana - Europeia sobre Governo dos Riscos, organizador Marcelo Dias Varella, Brasilia, 2005.2 Disponível em http://marcelodva.dominiotemporario.com/arquivos/Governo\%20dos\%20Riscos.pdf.

ESPIELL, Hector Gros. Los derechos económicos, sociales y culturales en el sistema interamericano. San Jose: Libri Libre, 1996. p. 16-17.

LEFF, Enrique. Saber ambiental: sustentabilidade, racionalidade, complexidade, poder. Tradução de Lucia Mathilde Endlich Orth. Petrópolis: Vozes, 2001.

LUCKÁCS, George. As bases ontológicas do pensamento e da atividade humana. Tradução de Lucia Mathilde Endlich Orth. Petrópolis: Vozes, 2001.

MACHADO, Paulo Leme. Direito Ambiental Brasileiro. São Paulo: Malheiros, 2011. 
MORATO LEITE, José Rubens. Dano Ambiental: do individual ao coletivo extrapatrimonial. São Paulo: RT, 2000.

Aspectos processuais do direito ambiental. Rio de Janeiro: forense Universitária, 2004.

MILARÉ, Edis. Direito do ambiente: doutrina, jurisprudência, prática, glossário. São Paulo: RT, 2012.

MUKAI, Toshio. Direito ambiental sistematizado. Rio de Janeiro: Forense Universitária, 1998.

PARDO, José Esteve. Técnica, riesgo y derecho: tratameiento del riesgo tecnológico em el derecho ambiental. Barcelona: Ariel, 1999.

PELIZZOLI, Marcelo Luiz. A emergência do paradigma ecológico: reflexões ético-filosóficas para o século XXIV. Petrópolis: Vozes, 1999.

PIOVESAN, Flávia. Direitos humanos e o direito constitucional internacional. São Paulo: Max Limonad, 2003.

PRINCIPIO; 15 da declaração final da conferência do Rio das Nações Unidas sobre meio ambiente e desenvolvimento. Disponível em: http://www.mma.gov.br/documentos/c. Acesso em: janeiro de 2006.

REHBINDER, Eckard. Politische und rechtliche Probleme des Veruursacherprinzips. Erich Schmidt Verlag, 1973, p.155.

SERRES, Michel. O contrato natural. Rio de Janeiro: Instituto Piaget, 1994.

TRINDADE, Antônio Augusto Cançado. Direitos humanos e meio ambiente: paralelo do sistema de proteção internacional. Porto Alegre: Sergio Fabris Editor, 1993.

Trabalho enviado em 18 de agosto de 2015.

Aceito em 17 de outubro de 2015. 